\title{
Acceptance and Use of Mobile Devices and Apps by Elderly People
}

\author{
Blanka Klimova
${ }^{1}$ Department of Applied Linguistics, Faculty of Informatics and Management, University of Hradec Kralove, Rokitanskeho 62, Hradec Kralove, 500 03, Czech Republic blanka.klimova@uhk.cz

\begin{abstract}
Currently, there is an increase in the number of older generation groups. These demographic changes obviously cause serious social and economic problems. Therefore, there is a need to prolong an active life of elderly people, who want to lead active, fulfilling and quality life in a sense of their inclusion, socialization and independence. This can be achieved not only by continuous support from their family members, but current trends show an important role of information and communication technologies (ICT) in this process. The purpose of this study is to explore the acceptance and use of mobile technology, specifically mobile devices and applications by elderly people, both from the technical and sociological point of view. The methods used in this study include a method of literature review of available sources, a method of comparison and evaluation of the findings from the selected studies on this topic. The findings show that although there is a number of mobile apps for the elderly on the market, they do not usually meet specific needs of these people such as their physical and cognitive impairments or relevant technical specifications of mobile device designed for this group of people. In addition, since the use of mobile technologies by elderly people is quite a new field of research, there are almost no research studies which would prove acceptance of these mobile apps. Therefore, there is a need of vast and detailed research in this area and also find a solution to this complex technological and sociological issue.
\end{abstract}

Keywords: Mobile Devices, Mobile Applications, Older People, Acceptance, Use.

\section{Introduction}

Ageing is becoming a big social issue nowadays. In 2000, the number of people at the age of $65+$ in the world reached $12.4 \%$ and this number is expected to grow to $19 \%$ by 2030 [1]. In developed countries, this number of older adults forms $24 \%$ and it should rise to $33 \%$ by 2050 [2]. In Europe the population group aged 65+ represents $18 \%$ of the 503 million Europeans, which should almost double by 2060 [3]. Compared to the world's data, this trend of aging population causes additional problems such as increased costs on the treatment and care about this elderly people [4-5]. 
Therefore, there is a need to prolong an active life of elderly people, who want to lead active, fulfilling and quality life in a sense of their inclusion, socialization and independence. This can be achieved not only by continuous support from their family members, but current trends show an important role of information and communication technologies (ICT) in this process. They are also known under the common name as gerontechnology because they try to meet the needs of aging society [6-7].

Furthermore, socio-scientific positions are used to develop a range of research that deals with the relationship between ICT and groups defined by gender, life cycle phases, or specific needs. An example is a study by Lubas, Mitchell, De Leo [8], which focuses on design and implementation of mobile applications (apps) that thanks to their construction enable their alternative form of communication to children with autistic disabilities to be tailored to their specific needs and to compensate for their communication barrier. The dynamic relationship between technology and aging is being systematically developed and becoming a narrowly defined area of interest. It uses social science theory to identify everyday ICT-related practices or needs, whose satisfaction requires a degree of user competencies or needs, whose satisfaction may be via ICT improved. Rogers, Stronge, Fisk [9] in Technology and Aging offer thematic areas in the everyday life of seniors that require research:

"...we address the extent to which older adults use new technologies, factors to consider in the adoption of technology (e.g., attitudes), the influence of technology design on older adults' performance (e.g., design of input devices), and ways to optimize training for older adults in using new technologies (e.g., age-specific instructional designs). We then review emerging areas of research that may direct the focus of human factors research in the next decade. These areas of research include ubiquitous computing (e.g., home monitoring systems), health care technologies (e.g., telehealth), robotics (e.g., Nursebot), and automated systems (e.g., cruise control). Finally, we consider opportunities and challenges to human factors research as the field continues to address the questions of optimizing technology for older adult users.” (p. 131)

An essential feature of this approach is the emphasis on optimizing technologies to adapt their design to the needs of aging users, which may not only have the nature of reduced capabilities and health restrictions [9]. Further studies show that the processes of digitalization and automation of public services may represent a hindrance for the elderly in their availability. Technological solutions often fail to take into account the specific (e.g., sensory) abilities of the elderly. The practical problems that arise from it are then attributed to blaming this class of actors for incompetence and other stereotyping and stigmatization. Criticism of this practice has highlighted the problem of technological normativity, which is the accompanying effect of socio-technical systems [10]. The authoritativeness and nobility of technological solutions that require unconditional adaptation from human actors is no longer obvious. Equal status of technical and human factors is developed using concepts of socio-technical systems, networking theory/material semiotics [11-14].

Although in the area of designing technological solutions in the last two decades, the user-centred research trend (UCD) has emerged, there is often no senior among model users. For this reason, already in 2001, a group of American researchers identified the UCD research strategy as "senior-centred research" that was applied to 
the design of medical information portals, for which the senior part of the population is quantitatively predominant clientele [15].

The purpose of this study is to explore the acceptance and use of mobile technology, specifically mobile devices and applications by elderly people, both from the technical and sociological point of view.

\section{Findings and discussion}

As research shows, elderly people are nowadays more digitally literate, especially those parents of baby boomers, and $80 \%$ of them have access to the Internet $[4,1617]$. Furthermore, there is an increasing number of those elderly people who own and use mobile devices, such as a mobile phone. For instance, $78 \%$ of older people at the age of 65+ own a mobile phone in the USA, as well as in the UK [18]. In the Czech Republic, it is $91 \%$ [19]. In fact, currently mobile devices seems to be more exploited than the desktop computers [20]. For example, $84 \%$ of elderly people in the Czech Republic (in 2014, 65+ seniors formed $17.4 \%$ of total population) use mobile phones every day [21], thus being even more passionate users than teenagers. The National Action Plan for active aging for the period of 2013 - 17 [22], approved by the Czech government in 2013, reflects the regional implementation strategy of the Madrid International Action Plan. Among others, it also pays attention to lifelong education. As stated by Sak, Kolesarova [23], current generation of seniors is the last to be literate in culture and the first to be changing quality of life with the help of a computer, the Internet and a mobile phone, thus crossing the generation gap between the culture and cyber-culture.

Although almost all people, including elderly population, own a mobile phone and some of them even use a smartphone, the number is still low. The reason of such a low number of elderly users is that a construction of these smartphones does not meet the specific needs of elderly people who require a mobile phone that is easy to use, provides safety and security, and is relatively cheap (e.g. [24-25]). Thus, specific needs of this group when using a mobile phone must be addressed. These are as follows [26-29]:

- Healthcare and monitoring the state of health needs: At present, there is an increasing number of elderly people who exploit the so-called mobile healthcare, i.e. remote care service due to the limitation of aged care resources. This remote care service might include, for example, obtaining information on their health, receiving reminders for scheduled visits, medication instructions, or consulting a doctor at a distance [30].

- Social Needs: Most elderly people live on their own and want to be in contact with their loved ones and friends. They also want to use the technologies their children like using.

- Leisure and sales needs: Personal leisure (entertainment or self-education) is important for senior citizens in what constitutes their free time occupation. They can also do shopping via mobile phones, order meals or play computer 
games in order to maintain quality of their life in case they are not able to go out regularly.

- Safety and privacy needs: This is considered as the most critical aspect for senior citizens. The user's activity must be monitored by using presence sensors and be analyzed with consideration to different scenarios.

On the basis of the older people's needs, the following apps seem to be the most suitable for them:

- Applications which convert the smartphone into a simpler and safer senior's mobile phone. Elderly people follow rooted stereotypes and archetypes, which is reflected in the use of mobile phones as well. They want their new, modern smartphones to possess the designs of old-fashioned land lines, with similar keypad and features in order to conduct all their daily tasks. In addition, they want to feel safe when they are home alone. Such an application which can meet these requirements is, for example, Koala Phone Launcher [31].

- Application and use of mobiles for healthcare or monitoring the state of health. Elderly people use mobile applications for monitoring their state of health or obtaining information about healthcare. This is especially true for people suffering from dementia or diabetes [32-33].

- Applications focused on entertainment [34], education and improvement of cognitive functions. Playing games help elderly people to spend their time in an entertaining way. In addition, it develops their memory, socializing and it has a positive impact on their psyche and overall state of health [35]. Some research studies [16] also prove that playing games can assist in the delay of Alzheimer's disease symptoms and other dementias.

However, since the use of mobile technologies by elderly people is quite a new field of research, there are almost no research studies which would prove acceptance of these mobile apps in the areas of the needs described above (cf. [36-37]).

For example, in the Web of Science 167 articles were found on the acceptance of mobile apps by the elderly (consult Fig. 1 below). The first one appeared already in 1996. However, most of the articles on the research issue started to be published after 2010 [38]. The topic of the majority of studies relates to health monitoring and assisted living technologies. This is not surprising since elderly people are mainly concerned at this age in maintaining their health conditions. The number of articles on the pure exploration of elderly people and their acceptance of technologies was relatively scarce. 


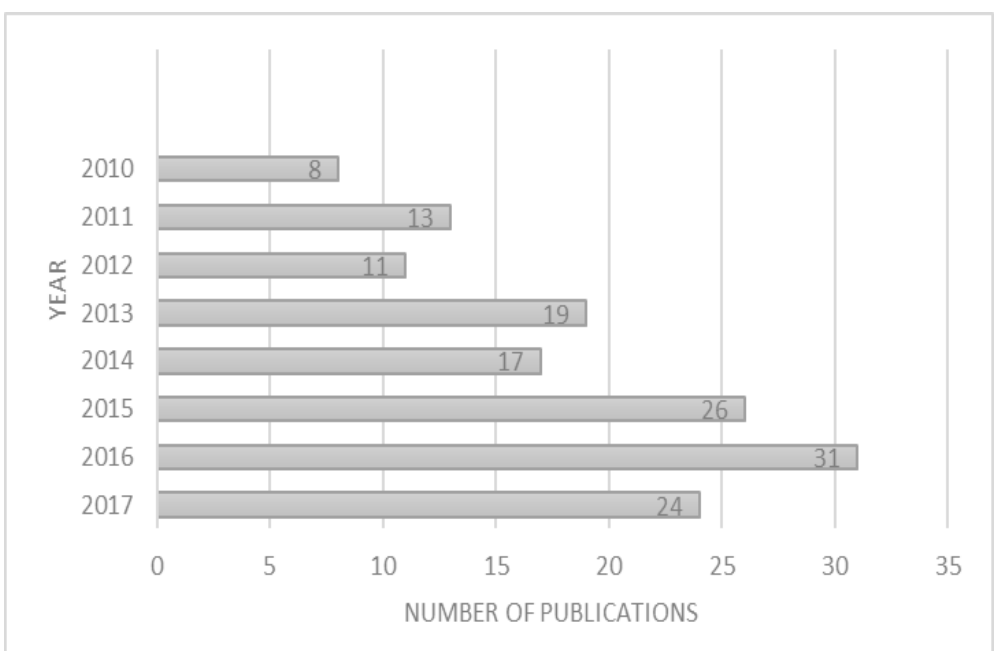

Fig. 1. An overview of the number of publications on the research topic in the Web of Science, authors' own processing based on the data from the Web of Science [11].

In the Czech Republic, there is no such research study, which would explore the acceptance and the use of mobile apps for the maintenance and improvement of quality of life for elderly people, specifically in the area of physical and cognitive activities, which as research studies show, can be maintained with an appropriate intervention. So far, there have been just a few projects, which, however, only focused on the use of the Internet by elderly (e.g., [39-41]). The similar situation can be observed in other European countries. Therefore, there is a need of vast and detailed research in this area and also find a solution to this complex technological and sociological issue.

\section{Conclusion}

Generally, there seem to be a number of mobile apps for the elderly on the market. However, they do not usually meet specific needs of these people such as their physical and cognitive impairments or relevant technical specifications of mobile device designed for this group of people. In addition, since the use of mobile technologies by elderly people is quite a new field of research, there are almost no research studies which would prove acceptance of these mobile apps. Therefore, there is a need of vast and detailed research in this area and also find a solution to this complex technological and sociological issue.

Acknowledgments. This study is supported by the SPEV project 2104/2018, run at the Faculty of Informatics and Management, University of Hradec Kralove, Czech Republic. The authors thank Josef Toman for his help with the data collection. 


\section{References}

1. Vafa, K.: Census bureau releases demographic estimates and projections for countries of the World, http://blogs.census.gov/2012/06/27/census-bureaureleasesdemographic-estimates-and-projections-for-countries-of-the-world/, last accessed 2018/1/29.

2. World population ageing 2013. UN, New York (2013).

3. Petterson, I.: Growing older. Tourism and leisure behaviour of older adults. Cabi, Cambridge (2006).

4. Klimova, B., Maresova, P., Kuca, K.: Non-pharmacological approaches to the prevention and treatment of Alzheimer's disease with respect to the rising treatment costs. Current Alzheimer Research 13(11), 1249-1258 (2016).

5. Maresova, P., Klimova, B., Kuca, K.: Alzheimer's disease: cost cuts call for novel drugs development and national strategy. Ceska a slovenska farmacie 64(1-2), 25-30 (2015).

6. Plaza, I., Martin, L., Martin, S., Medrano, C.: Mobile applications in an aging society: status and trends. The Journal of Systems and Software 84, 1977-1988 (2011).

7. Klimova, B., Valis, M.: Smartphone applications can serve as effective cognitive training tools in healthy aging. Front Aging Neurosci 9, 436 (2018).

8. Lubas, M., Mitchell, J., De Leo, G.: User-centered design and augmentative and alternative communication apps for children with autism spectrum disorders. Sage Open 4(2), 2158244014537501 (2014).

9. Rogers, W. A., Stronge, A. J., Fisk, A. D.: Technology and aging. Reviews of Human Factors and Ergonomics 1(1), 130-171 (2005).

10. Garrety, K., Badham, R.: User-centered design and the normative politics of technology. Science, Technology, \& Human Values 29(2), 191-212 (2004).

11. Pfaffenberger, B.: Social anthropology of technology. Annual review of Anthropology 21(1), 491-516 (1992).

12. Callon, M.: Actor-network theory-the market test. The Sociological Review 47(1_suppl), 181-195 (1999).

13. Latour, B.: Reassembling the social: An introduction to actor-network-theory. Oxford University Press (2005).

14. Law, J.: Actor network theory and material semiotics. The new Blackwell companion to social theory, 141-158 (2009).

15. Kwahk, J., Smith-Jackson, T. L., Williges, R. C.: From user-centered design to seniorcentered design: designing internet health information portals. In: Proceedings of the Human Factors and Ergonomics Society Annual Meeting, pp. 580-584, Los Angeles, CA, SAGE Publications (2001).

16. Heart, T., Kalderon, E.: Older adults: are they ready to adopt health-related ICT? International Journal of Medical Informatics 82, e209-e231 (2013).

17. Wu, Y.H., Damnee, S., Kerherve, H., Ware, C., Rigaud, A.S.: Bridging the digital divide in older adults: a study from an initiative to inform older adults about new technologies. Clinical Interventions in Aging 10, 193-201 (2015).

18. Pew Research Center. The demographics of device ownership, http://www.pewinternet.org/2015/10/29/the-demographics-of-device-ownership/, last accessed 2018/1/29.

19. Šimonová, I., Klímová, B., Poulová, P., Pražák, P.: The use of ICT devices by older people with a special focus on their type and respondents' age - a Czech case study. Educational Gerontology 43(12), 641-649 (2017). 
20. StatCounter. Mobile and tablet internet usage exceeds desktop for first time worldwide, http://gs.statcounter.com/press/mobile-and-tablet-internet-usageexceedsdesktop-for-first-time-worldwide, last accessed 2018/1/29.

21. Czech Statistical Office. Temer tri ctvrtiny Cechu jsou online. [Almost three fourths of the Czechs are online.], http://www.czso.cz/csu/tz.nsf/i/temer_tri_ctvrtiny_cechu_jsou_online_20141202, last accessed 2018/13/4.

22. Narodni akcni plan podporujici pozitivni starnuti pro obdobi let 2013 az 2017 [The National Action Plan for active aging for 2013 - 17 period], http://www.mpsv.cz/files/clanky/14540/NAP_2013-2017_070114.pdf., last accessed 2018/1/29

23. Sak, P., Kolesarova, K.: Sociologie stáríi a seniorů. (1st Ed.). Grada, Praha (2005).

24. Glasscock, N. F., Wogalter, M. S.: Evaluating preferences for mobile phone features. Proceedings of the Human Factors and Ergonomics Society 50th Annual Meeting. USA: San Francisco, 2006.

25. Mallenius, S., Rossi, M., Tuunainen, V.K.: Factors affecting the adoption and use of mobile devices and services by elderly people - results from a pilot study, http://citeseerx.ist.psu.edu/viewdoc/download?doi=10.1.1.130.2463\&rep=rep1\&type =pdf, last accessed 2018/1/29.

26. Chen, K., Chan, A.H.S.: Cell phone features preferences among older adults: a paired comparison study. Gerontechnology 13(2), 184 (2014).

27. Gao, J., Koronios, A.: Mobile application development for senior citizens, http://www.pacis-net.org/file/2010/S05-03.pdf, last accessed 2018/13/4.

28. Hameed, K.: The application of mobile computing and technology to health care services. Telematics and Informatics 20, 99-106 (2003).

29. Lapinsky, S.E.: Mobile computing in critical care. Journal of Critical Care 22, 41- 44 (2007).

30. Bujnowska-Fedak M. M., Pirogowicz, I.: Support for e-health services among elderly primary care patients. Telemedicine Journal and E-Health 20(8), 696-704 (2014).

31. Lipertova, M.: Koala Phone Launcher: promente smartphone na mobil pro seniory. [Koala Phone Launcher: convert the smartphone into a mobile phone for elderly people.], http://svetaplikaci.tyden.cz/koala-phone-launcher-promente-smartphonenamobil-pro-seniory/, last accessed 2018/1/29.

32. Amstrong, N., Nugent, C., Moore, G., Finlay, D.: Using smartphones to address the needs of persons with Alzheimer's disease. Ann. Telecommun, 65, 485-495 (2010).

33. Mangialasche, F., Kivipelto, M., Andrieu, S., Coley, N., Ngandu, T., Van Charante, E. M., et al.: Use of new technology to improve dementia prevention: the healthy aging through internet counseling in the elderly (HATICE) project. Alzheimer's. 881 (2013).

34. Vanden Abeele, V.A., Van Rompaey, V.: Introducing human-centered research to game design: designing game concepts for and with senior citizens. Proceedings of CHI 06 Extended Abstracts on Human Factors in Computing Systems. ACM, New York (2006).

35. Gerling, K.M., Schulte, F.P., Masuch, M.: Designing and evaluating digital games for frail elderly persons, http://dl.acm.org/citation.cfm?id=2071501, last accessed 2018/13/4.

36. Hedman, E., Ljotsson, B., Lindefors, N.: Cognitive behavior therapy via the Internet: a systematic review of applications, clinical efficacy and cost-effectiveness. Expert Rev Pharmacoecon Outcomes Res 12, 745-764 (2012). 
37. Klimova, B., Simonova, I., Poulova, P., Truhlarova, Z., Kuca, K.: Older people and their attitude to the use of information and communication technologies - A review study with special focus on the Czech Republic (Older people and their attitude to ICT). Educational Gerontology 42(5), 361-369 (2016).

38. Web of Science, http://apps.webofknowledge.com/Search.do?product=WOS\&SID=C2TMWq9F8rnn GhDVklU\&search_mode=GeneralSearch\&prID=da7f67df-a1b9-4a62b29d93c351c42a43, last accessed 2018/1/29.

39. AU3V ČR. Dlouhodobý záměr seniorského vzdělávání na vysokých školách na období 2008-2015 [Long-term plan of senior education at universities for the period of 2008-2015] (2007), http://au3v.vutbr.cz/soubory/DZ_AU3V_CR.doc, last accessed 2018/1/29.

40. Mannova, B., Bicik, J.: Projekt SEN-NET (older people in network), http://www.csvs.cz/konference/NCDiV2006_sbornik/Mannova.pdf, last accessed 2018/1/29.

41. Rain, T., Svarcova, I.: Internet and seniors. Journal on Efficiency and Responsibility in Education and Science 3(2), 79-85 (2010). 